\title{
Structure and luminescence properties of $\mathrm{K}_{2} \mathbf{G d F}_{5}: \mathbf{T b}^{3+}$ synthesized by solid-state reaction method
}

\author{
HA XUAN VINH ${ }^{1}$, NGUYEN CHI THANG ${ }^{1}$, DOAN PHAN THAO TIEN ${ }^{1}$ and BUI THE HUY ${ }^{2, *}$ \\ ${ }^{1}$ Nha Trang Institute of Technology Research and Application - VAST, 02 Hung Vuong, Nha Trang 650000, Vietnam \\ ${ }^{2}$ Department of Chemistry, Changwon National University, Changwon 51140, Korea \\ *Author for correspondence (buithehuy.nt@gmail.com)
}

MS received 4 July 2018; accepted 30 January 2019; published online 6 March 2019

\begin{abstract}
K}_{2} \mathrm{GdF}_{5}: \mathrm{Tb}^{3+}$ material used in dosimetry field was synthesized by solid-state reaction method. The scanning electron microscopy image showed that the material exhibits porous surface with a very large surface area. The photoluminescence spectrum confirmed energy transfer process from $\mathrm{Gd}^{3+}$ ions to $\mathrm{Tb}^{3+}$ ions, and the luminescence of this material was entirely due to $\mathrm{Tb}$ ions. The high luminescent intensity at $542 \mathrm{~nm}$ was perfectly consistent with the sensitive wavelength range of photomultiplier tubes in the thermoluminescence (TL) reader. The TL-glow curve was very simple with the temperatures of the main peak in the range from 200 to $230^{\circ} \mathrm{C}$, and the glow-curve shape was suitable for dosimetry purposes. The TL intensities of $\mathrm{K}_{2} \mathrm{GdF}_{5}: 10 \mathrm{~mol} \% \mathrm{~Tb}^{3+}$ was higher than that of common $\mathrm{CaSO}_{4}: \mathrm{Dy}^{3+}$ dosimeters. The estimation on available application of the prepared material in neutron dose measurement was carried out.
\end{abstract}

Keywords. $\mathrm{GdF}_{5}: \mathrm{Tb}^{3+} ; \mathrm{Gd}^{3+}-\mathrm{Tb}^{3+}$ ion pair; energy transfer; neutron dosimetry.

\section{Introduction}

Currently, the transfer of energy between rare-earth ions has been extremely significant in various applications, including optical devices, monitoring $\mathrm{X}$-ray and recording the radiation dose. The gadolinium host materials have also been investigated for doping the rare-earth ions into the structure, with dopants like $\mathrm{Sm}^{3+}, \mathrm{Pr}^{3+}, \mathrm{Tb}^{3+}, \mathrm{Er}^{3+}$ ions, etc. [1-6]. Among them, $\mathrm{Gd}^{3+}-\mathrm{Tb}^{3+}$ ion pairs have special properties, which are widely used in optical applications. For the $\mathrm{La}^{3+}$ rare-earth database the emission [7-9] wavelength of $\mathrm{Gd}^{3+}$ ion only locates at the short wavelength range $(<315 \mathrm{~nm})$, therefore, a phosphor with $\mathrm{Gd}^{3+}$, ion can emit in the visible light region which requires the presence of another rare-earth ion paired with $\mathrm{Gd}^{3+}$ ion. It is known that the $\mathrm{Tb}^{3+}$ ion has strong emission in the visible light region with maximum intensity at $542 \mathrm{~nm}$, so the $\mathrm{Tb}^{3+}$ ion has been suitable for this pairing. In addition, the transfer of energy from $\mathrm{Gd}^{3+}$ to $\mathrm{Tb}^{3+}$ is so efficient that the $\mathrm{Gd}^{3+}$ ion is activated as an energyabsorbing centre and the $\mathrm{Tb}^{3+}$ ion acts as a luminescence centre [10-13].

The study on new material use as a dosimeter in the nuclear radiation field has been essential, however, only a few materials have been used to measure the dose by the thermoluminescence (TL) method until now [14,15]. Recently, the materials based on fluoride-doped rare-earth ions have been studied, in particular, $\mathrm{K}_{2} \mathrm{GdF}_{5}$ doped with $\mathrm{Dy}^{3+}, \mathrm{Pr}^{3+}, \mathrm{Sm}^{3+}$, $\mathrm{Tb}^{3+}$ possess remarkable TL properties [16,17].

Due to the thermal neutron absorption of $\mathrm{Gd}^{3+}$ ion which is the highest among natural elements (thermal neutron cross-section $=4.9 \times 10^{4}$ barns), the interaction of the $\mathrm{K}_{2} \mathrm{GdF}_{5}$ with neutron beam is very strong and can be used as a neutron dosimeter by the TL method. Several studies have shown that the $\mathrm{K}_{2} \mathrm{GdF}_{5}: \mathrm{Tb}^{3+}$ has very high TL intensity and the TL-glow curve shape of $\mathrm{K}_{2} \mathrm{GdF}_{5}: \mathrm{Tb}^{3+}$ is simple with a clear dosimetry peak [18-21]. To the best of our knowledge, there is no detailed investigation on optical properties, morphologies and TL of this material. In this paper, we report the structure and luminescence properties of $\mathrm{K}_{2} \mathrm{GdF}_{5}: \mathrm{Tb}^{3+}$ samples, which were synthesized by solid-state reaction method. Moreover, the response on thermal neutron beam of prepared material is also presented.

\section{Experimental}

$\mathrm{K}_{2} \mathrm{GdF}_{5}$ phosphors doped with terbium ions were synthesized by a solid-state reaction:

$$
2 \mathrm{KF}+(1-x) \mathrm{GdF}_{3}+x \mathrm{TbF}_{3} \rightarrow \mathrm{K}_{2} \mathrm{Gd}_{(1-x)} \mathrm{Tb}_{x} \mathrm{~F}_{5}
$$

where $x=5,10,15,20 \mathrm{~mol} \%$.

The raw materials of $\mathrm{KF}, \mathrm{GdF}_{3}$ and $\mathrm{TbF}_{3}$ powder with 99.99\% pure by grade were purchased from Aldrich Ltd. The mixture of raw materials were thoroughly mixed in an agate mortar for $2 \mathrm{~h}$ in a glove-box with argon gas, then the homogeneous mixture was placed in a graphite tube, for calcination in an electric furnace at $620^{\circ} \mathrm{C}$ for 5 days under $\mathrm{N}_{2}$ gas. After heating, the product was crushed to micrometre-sized 
particles, and then washed with distilled water and ethanol several times to remove excess materials. Then, the powder was dried at $120^{\circ} \mathrm{C}$ for $30 \mathrm{~min}$, and then annealed at $400^{\circ} \mathrm{C}$ for $60 \mathrm{~min}$ to obtain fine white powder.

The phase identification of $\mathrm{K}_{2} \mathrm{GdF}_{5}: \mathrm{Tb}^{3+}$ samples was characterized by an X-ray diffractometer X'Pert from PANalytical with $\mathrm{CuK} \alpha\left(\right.$ ratio $\mathrm{K}_{\alpha 2} / \mathrm{K}_{\alpha 1}=0.5$ ) radiation. The scans of selected diffraction peaks were carried out in step mode, in the $2 \theta$ range from 15 to $70^{\circ}$, step $0.01^{\circ}$, and the measurement temperature was $25^{\circ} \mathrm{C}$. The morphology of the powder samples, which were pasted on the carbon tape, were conducted using a scanning electron microscope (SEM) by the MIRA-II Tescan instrument (Czech), operated at $20 \mathrm{kV}$.

The photoluminescence (PL) measurements were performed on the Horiba JobinYvon FL3-22, resolution of $0.5 \mathrm{~nm}$ using the excitation wavelength at $275 \mathrm{~nm}$, and the excitation spectra were also measured on this instrument by a monitor wavelength at $542 \mathrm{~nm}$. The absorption spectra were obtained by using a diffuse reflectance in UV-Vis spectrophotometer V670 (Jasco, Japan) with integrating sphere ILN-725 (150 mm).

For studying TL properties, the samples were irradiated with various radiation sources, such as: the ${ }^{60} \mathrm{Co}$ gamma source with $0.5 \mathrm{~Gy} \mathrm{~s}^{-1}$ dose rate, ${ }^{90} \mathrm{Sr} /{ }^{90} \mathrm{Y}$ beta with $1.2 \mathrm{~Gy} \mathrm{~min}^{-1}$ dose rate and ${ }^{241} \mathrm{Am} / \mathrm{Be}$ neutron source, the neutron beam $\left(10^{7} \mathrm{n} \mathrm{s}^{-1}\right)$ with average energy $E_{\text {avr }}=4.459 \mathrm{MeV}$. The TL characteristics were investigated by the Harshaw TLD3500 instrument with the WINREMS program. The heattreatment range, heating rate were from 50 to $400^{\circ} \mathrm{C}, 2$ and $10^{\circ} \mathrm{C} \mathrm{s}^{-1}$, respectively. The weight of sample on each TL measurement is $20 \mathrm{mg}$. The TL-glow curves were plotted from data exported by the WINREMS program (Harshaw) for determining the values of the peaks and TL intensities.

\section{Results and discussion}

\subsection{Crystal structure}

Figure 1 displays the X-ray diffraction (XRD) spectra of $\mathrm{K}_{2} \mathrm{GdF}_{5}$ doped with $5,10,15$ and $20 \mathrm{~mol} \%$ of $\mathrm{Tb}^{3+}$ concentrations. Most of the diffraction peaks are consistent with the orthorhombic structure of $\mathrm{K}_{2} \mathrm{GdF}_{5}$ and $\mathrm{K}_{2} \mathrm{TbF}_{5}$, and the diffraction peaks of this pattern match with the Miller index of $\mathrm{K}_{2} \mathrm{GdF}_{5}$ by JCPDS no. 77-1924. In addition, XRD pattern has demonstrated that the doping of terbium does not change the structure of $\mathrm{K}_{2} \mathrm{GdF}_{5}$ host material. In particular, figure 2 shows that $\mathrm{K}_{2} \mathrm{GdF}_{5}: 10 \mathrm{~mol} \% \mathrm{~Tb}$ sample has clear peaks with the highest intensity.

Average crystalline size of $\mathrm{K}_{2} \mathrm{GdF}_{5}: \mathrm{Tb}^{3+}$ sample doped with $20,15,10$ and $5 \mathrm{~mol} \%$ to be $38 \pm 2,45 \pm 1.5,74 \pm 2$ and $42 \pm 1.5 \mathrm{~nm}$, respectively, obtained from XRD patterns using the Scherrer equation were consistent with the respective SEM data. The crystal structure of $\mathrm{K}_{2} \mathrm{GdF}_{5}: 10 \mathrm{~mol} \%$ $\mathrm{Tb}^{3+}$ was simulated by Diamond software. The material has been crystallized in the orthorhombic structure (62) with the space group of Pnam. Figure 3 a shows the $\mathrm{K}^{+}$cation, which is

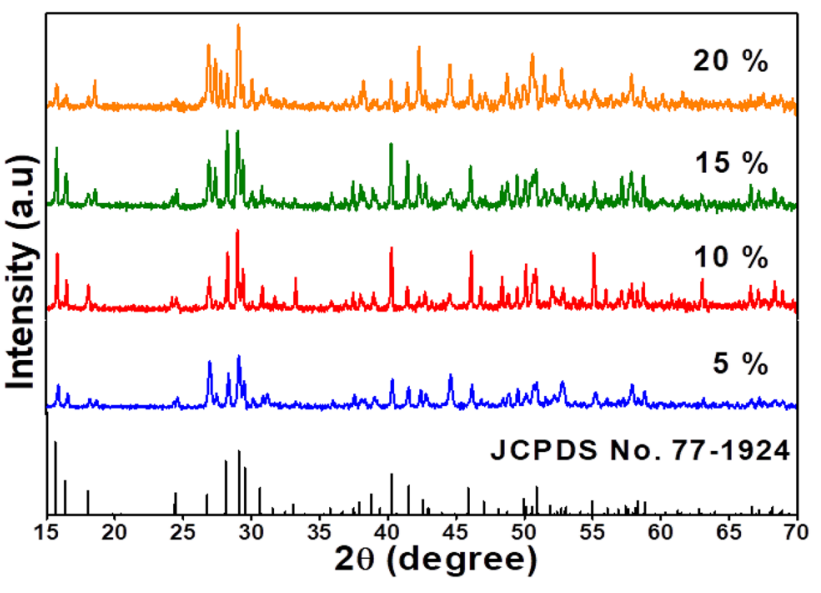

Figure 1. XRD pattern of $\mathrm{K}_{2} \mathrm{GdF}_{5}: \mathrm{Tb}^{3+}$ with various $\mathrm{Tb}$ concentrations.

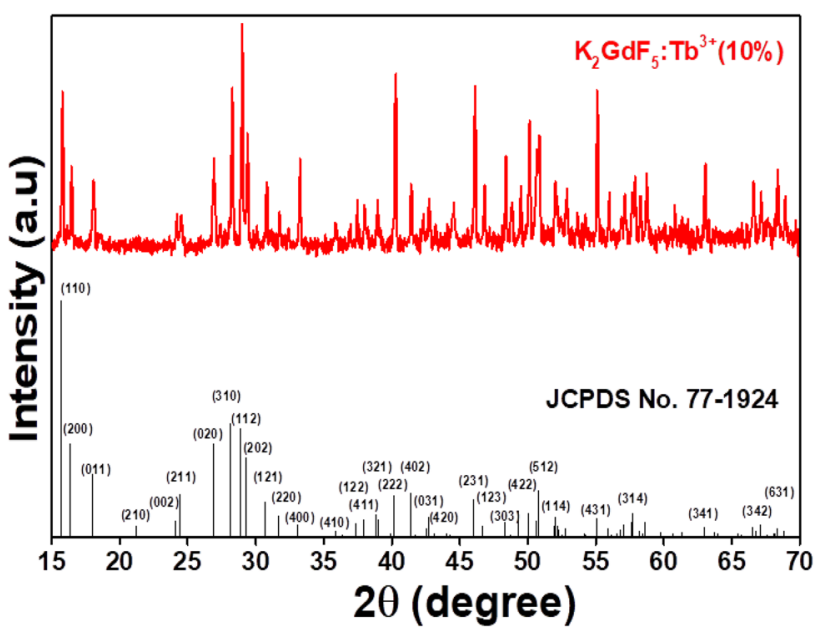

Figure 2. XRD pattern of $\mathrm{K}_{2} \mathrm{GdF}_{5}$ doped with $10 \% \mathrm{~Tb}^{3+}$.

surrounded by eight $\mathrm{F}^{-}$anions. Each $\mathrm{Gd}^{3+}$ cation lies in a $D_{2 h}$ symmetry site and is connected to seven $\mathrm{F}^{-}$anions, forming the $\mathrm{GdF}_{7}$ polyhedron. The polyhedra are connected by a common edge and form a chain parallel to the $c$-axis. This one-dimensional structure of the sample has great influence on the energy transfer properties among $\mathrm{Gd}^{3+}$ sub-lattices.

The cell parameters of $\mathrm{K}_{2} \mathrm{GdF}_{5}: 10 \mathrm{~mol} \% \mathrm{~Tb}^{3+}$ are $a=$ $10.81 \AA, b=6.623 \AA, c=7.389 \AA$. When doping with $\mathrm{Tb}^{3+}$ ion in $\mathrm{K}_{2} \mathrm{GdF}_{5}$ host lattice, the $\mathrm{Gd}^{3+}$ ions will be replaced by the $\mathrm{Tb}^{3+}$ ions because the ionic radius of $\mathrm{Tb}^{3+} \sim 109.5 \mathrm{pm}$ is approximately to $\mathrm{Gd}^{3+} \sim 110.7 \mathrm{pm}$ (figure $3 \mathrm{~b}$ ). According to Russ. J. Inorg. Chem., 1990 published by the National Institute of Materials Science (Japan), the crystal structure map and the X-ray diffusion schema of $\mathrm{K}_{2} \mathrm{GdF}_{5}$ and $\mathrm{K}_{2} \mathrm{TbF}_{5}$ are almost identical, so on replacing $\mathrm{Gd}^{3+}$ ions by $\mathrm{Tb}^{3+}$ ions, the crystal lattice structure of host material $\mathrm{K}_{2} \mathrm{GdF}_{5}$ is almost unchanged. 
a
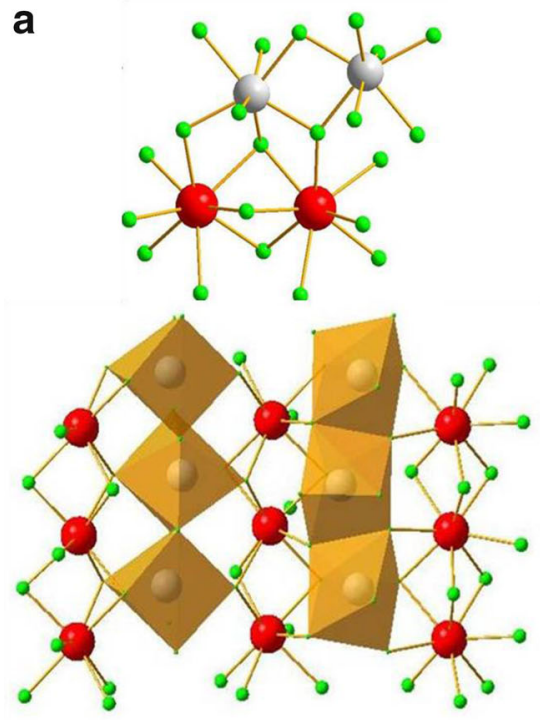

b

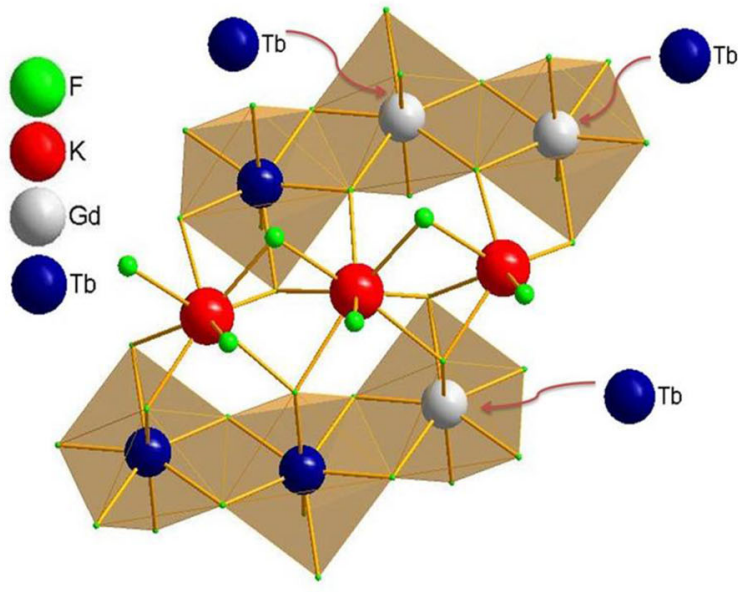

Figure 3. Crystal structure of $\mathrm{K}_{2} \mathrm{GdF}_{5}: \mathrm{Tb}^{3+}$ : (a) the coordination polyhedra of $\mathrm{Gd}^{3+}$ and $\mathrm{F}^{-}$in $\mathrm{K}_{2} \mathrm{GdF}_{5}$ crystal and (b) the replacement of $\mathrm{Tb}$ ions in the position of $\mathrm{Gd}$.

\subsection{Surface morphology}

Surface morphology of the material shows uniform distribution, the structure depends on the grinding mode of the components, proving that in the synthesis process, the material does not melt and does not form big clusters of components. So, it can be concluded that the doping process is very uniform in the material with a correct ratio of components.

The surface morphology of $\mathrm{K}_{2} \mathrm{GdF}_{5}: \mathrm{Tb}^{3+}$ powder is presented by SEM images in figure 4, the rough surface of the material structure is due to the distribution of uniform beads at a size of $<100 \mathrm{~nm}$. This result was consistent with the data obtained from XRD patterns. Figure 4 shows the change of surface morphology by the $\mathrm{Tb}^{3+}$ ion-doped concentrations, in other words, $\mathrm{Tb}^{3+}$ ion influences the morphology of the material. The results also indicate that at the concentration of $5 \mathrm{~mol} \% \mathrm{~Tb}^{3+}$, the bead clusters start appearing on the surface, but this appearance is random and overlapping. The density of the particles increases with the increase in doping concentration, as shown in figure $3 \mathrm{~b}-\mathrm{d}$. However, at $15 \mathrm{~mol} \%$ doping, it shows a surface with smooth beads covering around the host particles. At $20 \mathrm{~mol} \%$ doping, the bead distribution is higher, but they are not uniform and appear as thick clusters of beads.

In particular, the sample doped with $\mathrm{Tb}^{3+} 10 \mathrm{~mol} \%$ concentration has an optimum surface morphology when the beads are uniform, do not overlap, with high density and appears like a vertical partition on the host particle surface. These surface morphological results are very well correlated with the fluorescence properties. This can be explained by the large porous surface area as well as the uniformity of the vertical partition beads on the $10 \mathrm{~mol} \%$ doping sample surface.

\subsection{PL properties}

PL spectrum of $\mathrm{K}_{2} \mathrm{GdF}_{5}: \mathrm{Tb}^{3+}$ in the wavelength range of $300-650 \mathrm{~nm}$ is measured at excitation wavelength of $275 \mathrm{~nm}$, and it is shown in figure $5 \mathrm{a}$. The fluorescent measurements of $\mathrm{K}_{2} \mathrm{GdF}_{5}: \mathrm{Tb}^{3+}$ shows that the emission spectrum consisting main peaks located at $622,585,542$ and $485 \mathrm{~nm}$ corresponding to the ${ }^{5} \mathrm{D}_{4} \rightarrow{ }^{7} \mathrm{~F}_{\mathrm{J}}$ transitions $(J=3,4,5,6)$ of $\mathrm{Tb}^{3+}$ ions. In particular, the highest emission intensity corresponds to the ${ }^{5} \mathrm{D}_{4} \rightarrow{ }^{7} \mathrm{~F}_{5}$ transition at $542 \mathrm{~nm}$. Moreover, the $\mathrm{K}_{2} \mathrm{GdF}_{5}$ sample did not fluoresce in the range of $400-600 \mathrm{~nm}$, and the emission spectrum of $\mathrm{K}_{2} \mathrm{TbF}_{5}$ sample was similar with the emission spectra of $\mathrm{K}_{2} \mathrm{GdF}_{5}: \mathrm{Tb}^{3+}$. In summary, the PL spectrum also demonstrates that the luminescence centres of the material are purely due to the $\mathrm{Tb}^{3+}$ ions.

Figure $5 \mathrm{~b}$ displays the excitation spectra of $\mathrm{K}_{2} \mathrm{GdF}_{5}$ : $10 \mathrm{~mol} \% \mathrm{~Tb}^{3+}, \mathrm{K}_{2} \mathrm{GdF}_{5}$ and $\mathrm{K}_{2} \mathrm{TbF}_{5}$. The excitation peak with the highest intensity locate at $275 \mathrm{~nm}$, which corresponds to the absorption displacement of $\mathrm{Gd}^{3+}$ ion. The other spectral lines of $\mathrm{Tb}^{3+}$ ion in the range of $250-300 \mathrm{~nm}$ were not observed.

Thus, $\mathrm{Gd}^{3+}$ ion clearly has a role in the absorption of excited energy, and the excitation displacement at $275 \mathrm{~nm}$ from ground to ${ }^{6} \mathrm{I}_{\mathrm{J}}$ level, has the highest intensity. In particular, the stimulation transitions at $312 \mathrm{~nm}$ corresponding to the displacements from the ${ }^{8} \mathrm{~S}_{7 / 2}$ base level to the ${ }^{6} \mathrm{P}_{\mathrm{J}}$ excited levels of ion $\mathrm{Gd}^{3+}$ are very high, but conversely the ${ }^{6} \mathrm{P}_{\mathrm{J}} \rightarrow{ }^{8} \mathrm{~S}_{7 / 2}$ emission transitions $(312 \mathrm{~nm})$ are not detected in the PL spectrum. Thus, with the existence of the $\mathrm{Gd}^{3+}-\mathrm{Tb}^{3+}$ ion pair, the stimulating energies of the ${ }^{6} \mathrm{P}_{\mathrm{J}},{ }^{6} \mathrm{I}_{\mathrm{J}}$ and ${ }^{6} \mathrm{D}_{\mathrm{J}}$ levels of $\mathrm{Gd}^{3+}$ ions can be efficiently transferred to $\mathrm{Tb}^{3+}$ ions. These processes enhance the luminescence in the visible range of the phosphor. 

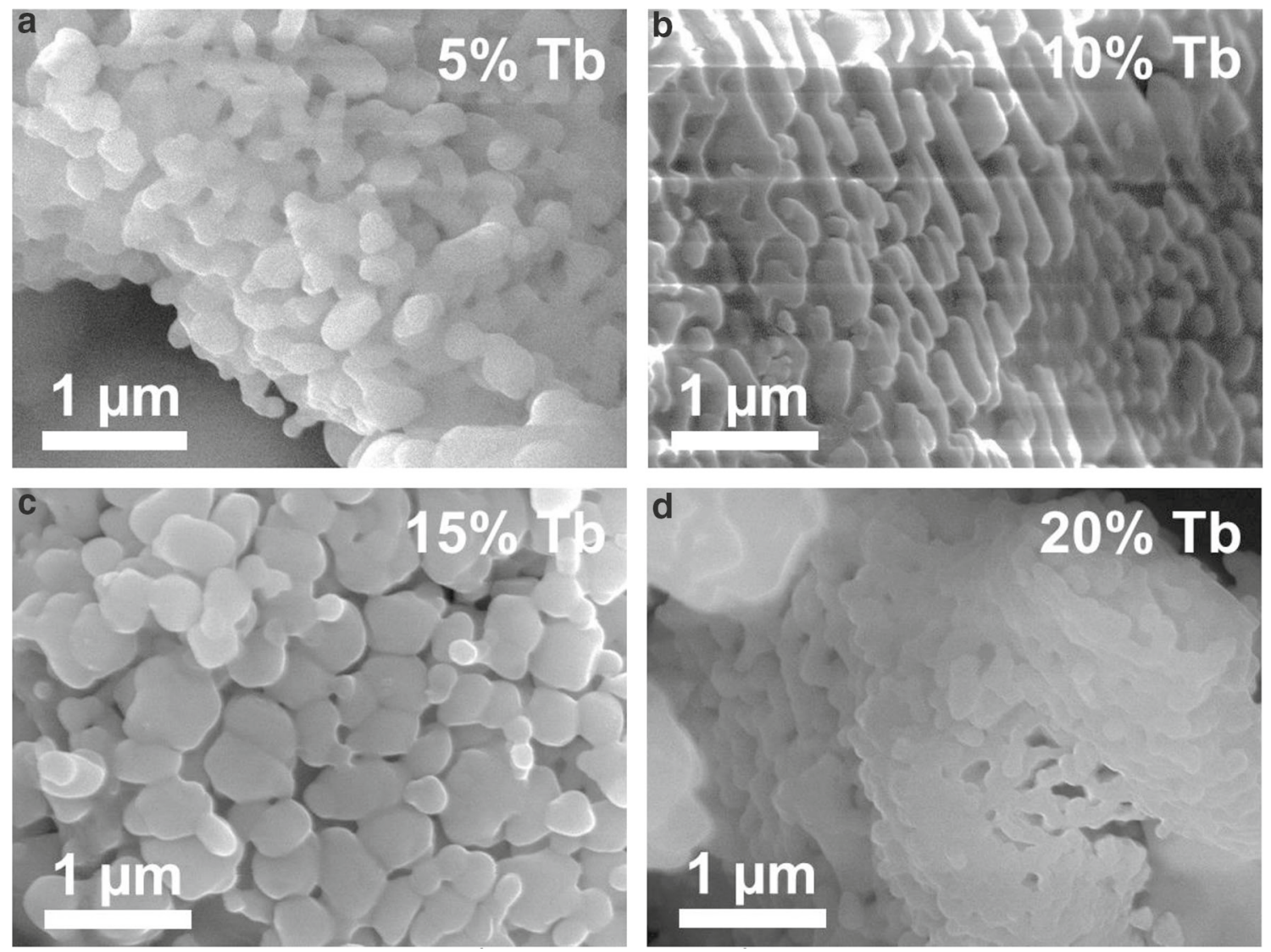

Figure 4. $\mathrm{SEM}$ images of $\mathrm{K}_{2} \mathrm{GdF}_{5}: \mathrm{Tb}^{3+}$ with various $\mathrm{Tb}^{3+}$ concentrations.
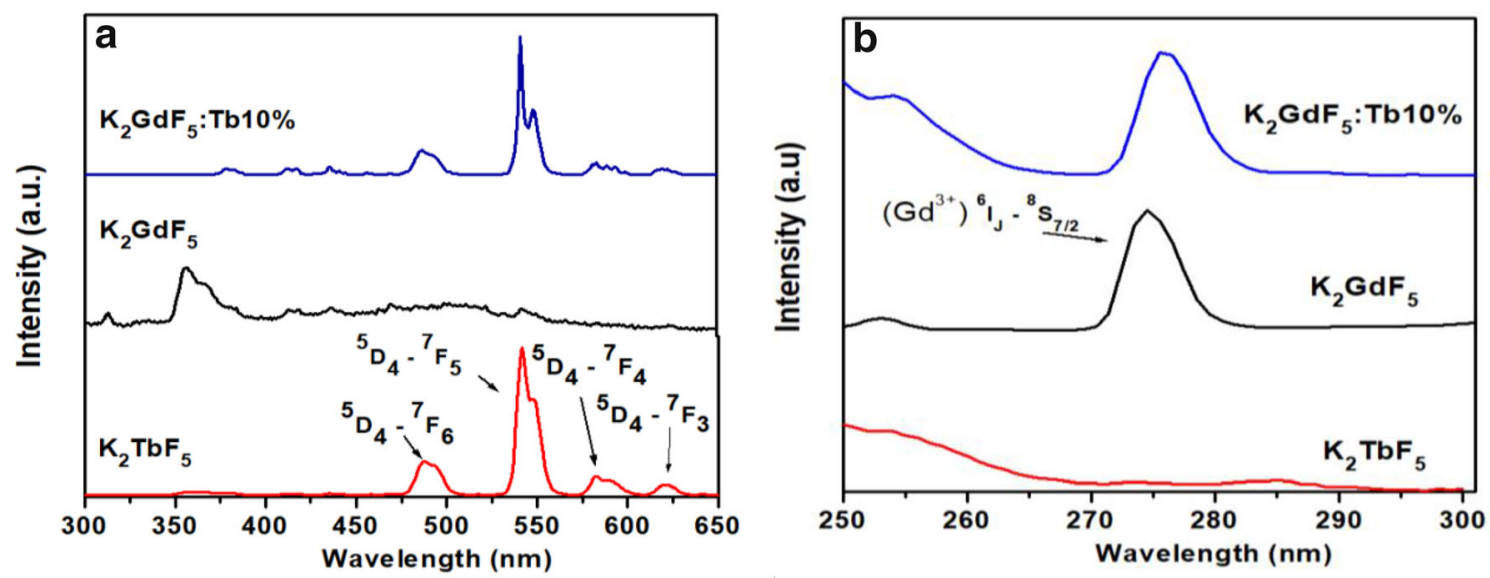

Figure 5. (a) PL spectra and (b) excitation spectra of $\mathrm{K}_{2} \mathrm{GdF}_{5}: 10 \mathrm{~mol} \% \mathrm{~Tb}, \mathrm{~K}_{2} \mathrm{GdF}_{5}$ and $\mathrm{K}_{2} \mathrm{TbF}_{5}$.

The absorption spectrum was obtained by the diffuse reflectance of the $\mathrm{K}_{2} \mathrm{GdF}_{5}: 10 \mathrm{~mol} \% \mathrm{~Tb}^{3+}$ phosphor, as shown in figure 6a. The spectrum indicates that the absorption peaks at 375 and $485 \mathrm{~nm}$ correspond to the energy levels ${ }^{5} \mathrm{D}_{4}$ and ${ }^{5} \mathrm{D}_{3}$ of $\mathrm{Tb}^{3+}$ ion. Thus, the quantum transfer mechanism in the material will follow the rules shown in figure $6 \mathrm{~b}$. When the $\mathrm{Gd}^{3+}$ ion receives the excited energy, the energy of ${ }^{6} \mathrm{P}_{\mathrm{J}},{ }^{6} \mathrm{I}_{\mathrm{J}}$ and
${ }^{6} \mathrm{D}_{\mathrm{J}}$ levels will be transmitted to the ${ }^{5} \mathrm{H}_{\mathrm{J}},{ }^{5} \mathrm{~F}_{\mathrm{J}}$ and ${ }^{5} \mathrm{~K}_{\mathrm{J}}$ levels of the $\mathrm{Tb}^{3+}$ ion by $\mathrm{T} 1, \mathrm{~T} 2$ and $\mathrm{T} 3$ processes, respectively.

$\mathrm{Tb}^{3+}$ ion has many energy levels in the range $(25-40) \times$ $10^{3} \mathrm{~cm}^{-1}$, and according to Dieke, this area has 36 levels based on $5 \mathrm{D}, 5 \mathrm{G}, 5 \mathrm{~L}, 5 \mathrm{H}, 5 \mathrm{~F}, 5 \mathrm{~K}$ states, which are quite close together $\left(\sim 10^{3} \mathrm{~cm}^{-1}\right.$ spacing). So the $\mathrm{Tb}^{3+}$ ion quite easily shows non-radiated transfer to the ${ }^{5} \mathrm{D}_{3}$ and ${ }^{5} \mathrm{D}_{4}$ levels, and 

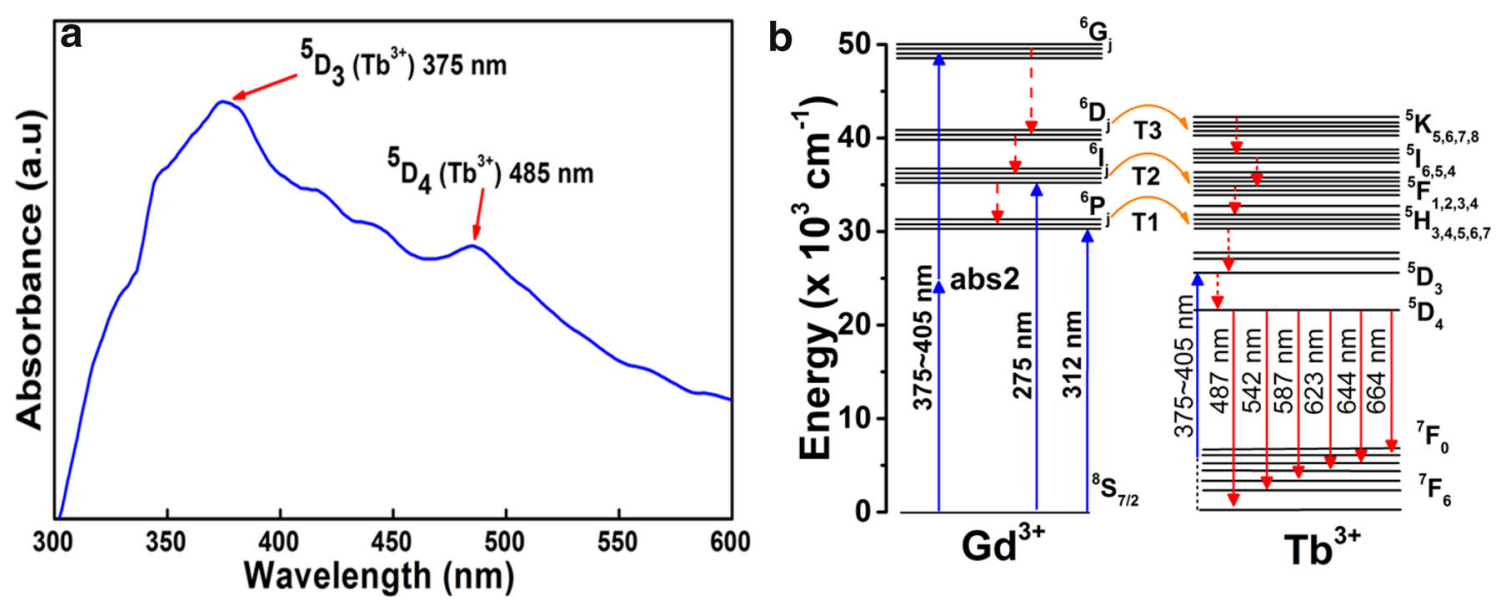

Figure 6. (a) Absorption spectrum of the $\mathrm{K}_{2} \mathrm{GdF}_{5}: 10 \mathrm{~mol} \% \mathrm{~Tb}^{3+}$ phosphor. (b) Schematic of energy levels and mechanisms for the quantum transformation of $\mathrm{K}_{2} \mathrm{GdF}_{5}: \mathrm{Tb}^{3+}$.
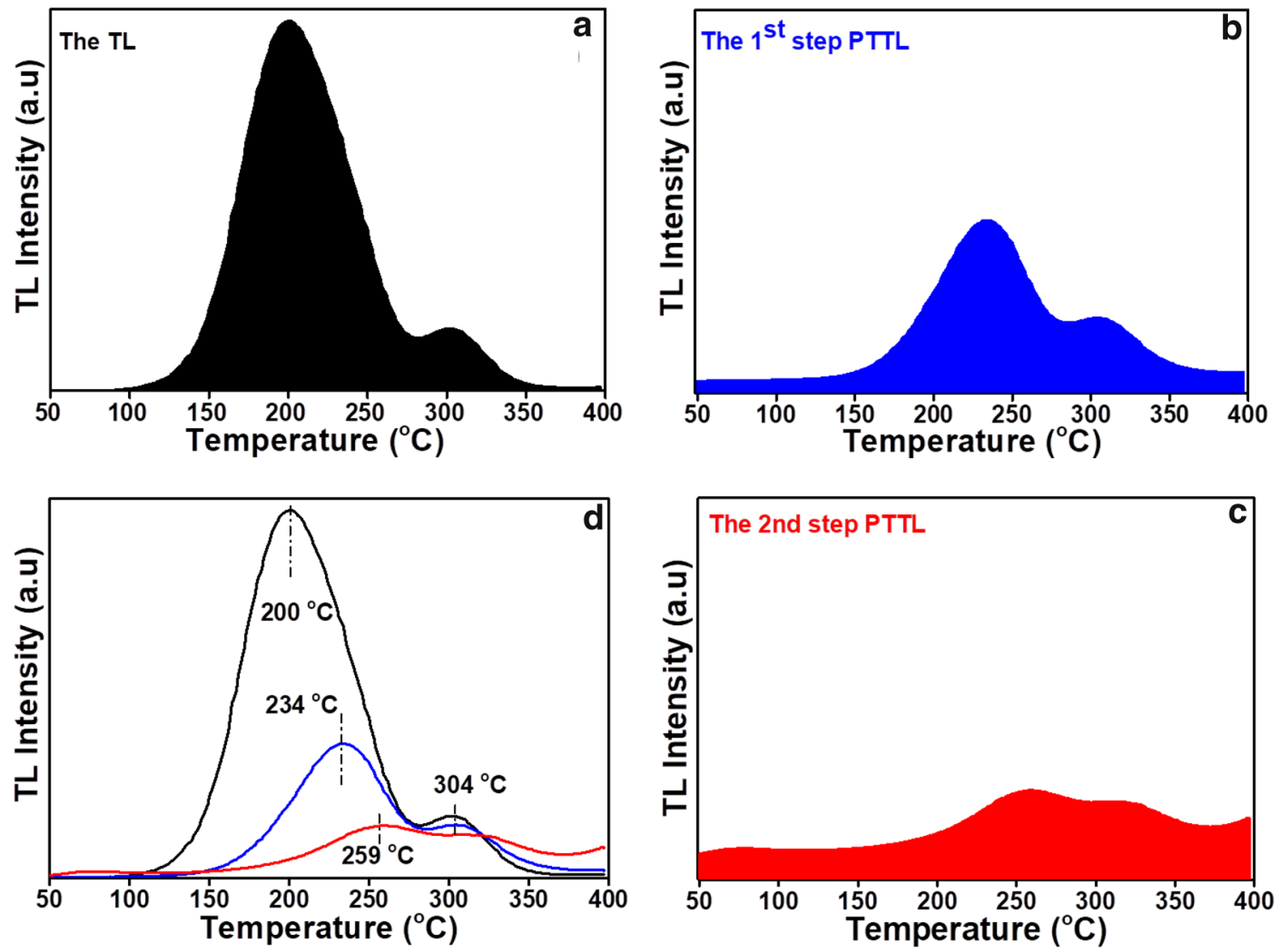

Figure 7. Glow curves of $\mathrm{K}_{2} \mathrm{GdF}_{5}: 10 \mathrm{~mol} \% \mathrm{~Tb}$. (a) TL-glow curve, (b) the first PTTL-glow curve, (c) the second PTTL-glow curve and (d) temperature of the single peaks in the TL-glow curve.

then they will transfer to the ground with radiating lines in the visible region shown in figure $5 \mathrm{a}$. The intensity of the transfer from ${ }^{5} \mathrm{D}_{3}$ to the ground level (range $375-405 \mathrm{~nm}$ ) is less dependent on the $\mathrm{Tb}^{3+}$ concentration and is very weak compared to the transfer from ${ }^{5} \mathrm{D}_{4}$ level, while the absorption at the range of $375 \mathrm{~nm}$ due to ${ }^{5} \mathrm{D}_{3}$ is quite high (figure $6 \mathrm{a}$ ). Thus, it is indicated that there exists two-photon absorption in the wavelength range $375-405 \mathrm{~nm}$, and this mechanism can be described by the 'abs2' process in figure $6 \mathrm{~b}$. These results are quite consistent with studies on the energy transfer 
of Gd-Tb pair in different materials [22-24] and the radiation wavelength range of $\mathrm{K}_{2} \mathrm{GdF}_{5}: \mathrm{Tb}^{3+}$ phosphor has advantages in optical measurement applications.

\subsection{TL properties}

3.4a Characteristic of TL-glow curve: The $\mathrm{K}_{2} \mathrm{GdF}_{5}$ : $10 \mathrm{~mol} \% \mathrm{~Tb}^{3+}$ sample was irradiated by ${ }^{60} \mathrm{Co}$ gamma source at $20 \mathrm{~Gy}$ dose, then the TL properties were investigated by using a TLD 3500 instrument at a heating rate of $2^{\circ} \mathrm{C} \mathrm{s}^{-1}$. The TL-glow curve has a dominant peak at $200^{\circ} \mathrm{C}$ and a low peak at $304^{\circ} \mathrm{C}$, as shown in figure $7 \mathrm{a}$. In the down slope of the main peak, there are some low individual peaks covered by the main peak.

To identify these single peaks, the photo-transferred TL (PTTL) method is used. After the TL measurement, all the electrons in the trap corresponding to the main peak have been released, but electrons in the deeper traps have not yet been released. The PTTL measurement was performed with the deuterium (D2) lamp support to irradiate the ultraviolet light on samples and again TL was measured. Figure 7b and $\mathrm{c}$ shows PTTL-glow curve of the $\mathrm{K}_{2} \mathrm{GdF}_{5}: 10 \mathrm{~mol} \% \mathrm{~Tb}$ sample, which was irradiated by ${ }^{60} \mathrm{Co}$ gamma source with $20 \mathrm{~Gy}$ dose. After the TL measurement (results shown in figure 7a), the traps corresponding to temperatures below $400^{\circ} \mathrm{C}$ were erased, but electrons remained in deeper traps were not released. The sample was irradiated by ultraviolet light from a D2 lamp for $10 \mathrm{~min}$, and the TL signal was measured again. The results of this measurement show that the appearance of the old peak at $304^{\circ} \mathrm{C}$ and a new peak at $234^{\circ} \mathrm{C}$ is very clear (figure $7 \mathrm{~b}$ ). The peak at $234^{\circ} \mathrm{C}$ does not appear during the first TL measurement because it is obscured by the very high-intensity peak at $200^{\circ} \mathrm{C}$. When the sample was irradiated by the $\mathrm{D} 2$ lamp, electrons in deep traps received energy and moved to shallower trap levels, but not enough energy enter the trap level corresponding to the $200^{\circ} \mathrm{C}$ peak, so, the first PTTL measurement shows the peak which is behind the main peak.

Again, the samples were continued to be irradiated for 10 min by the D2 lamp and the TL signal was measured. The result of the second PTTL measurement (figure 7c) shows the peak still at $304^{\circ} \mathrm{C}$, besides the appearance of a new peak at $259^{\circ} \mathrm{C}$, while the peak at $234^{\circ} \mathrm{C}$ is almost disappeared. The TL intensity is very low, indicating that the electron concentrations in the deep traps have been exhausted.

Thus, with the PTTL method and the UV-assisted, the single peaks appeared more clearly without overlapping (figure 7d). The results show that the glow curve of $\mathrm{K}_{2} \mathrm{GdF}_{5}$ : $\mathrm{Tb}^{3+}$ includes the main peak at $200^{\circ} \mathrm{C}$ and other single peaks at 234,259 and $304^{\circ} \mathrm{C}$. The TL intensity of the main peak (dosimetry peak) is very high compared to the lateral peaks, the TL-glow curve has been of simple shape and the radiation dose determination is convenient.

3.4b TL response to beta dose: The beta source investigation results also showed that TL-curve shapes were similar

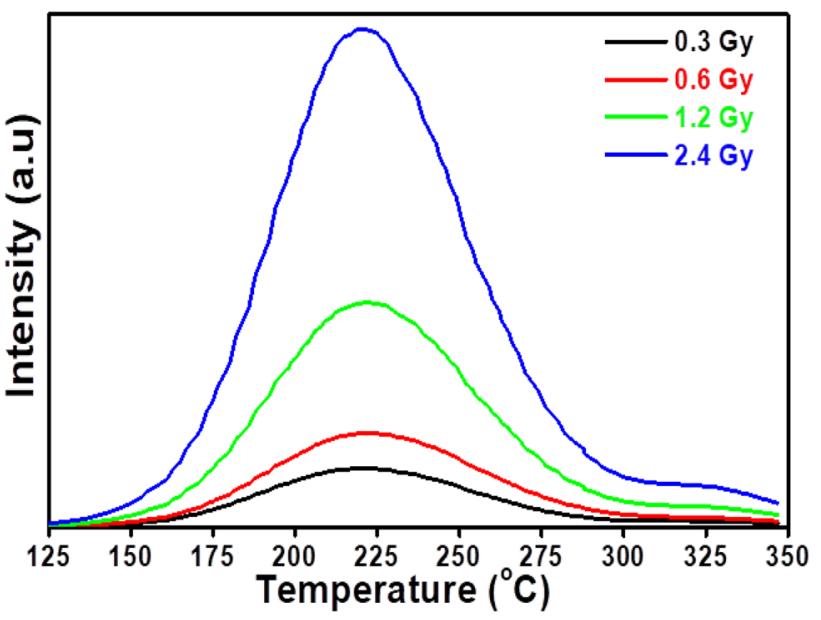

Figure 8. TL curves of the $\mathrm{K}_{2} \mathrm{GdF}_{5}: 10 \mathrm{~mol} \% \mathrm{~Tb}^{3+}$ irradiated by ${ }^{90} \mathrm{Sr} /{ }^{90} \mathrm{Y}$ beta source.

to gamma irradiation case. Figure 8 shows the TL response of the $\mathrm{K}_{2} \mathrm{GdF}_{5}: 10 \mathrm{~mol} \% \mathrm{~Tb}^{3+}$ with the beta radiation and the TL-glow curves were measured from 50 to $350^{\circ} \mathrm{C}$ with a $10^{\circ} \mathrm{C} \mathrm{s}^{-1}$ heating rate. All the TL curves had the dosimetry peaks at $223^{\circ} \mathrm{C}$ and the glow curves of various doses were very uniform with the TL intensity proportional to the dose.

3.4c The TL response to neutron dose: The energy transfer issue from $\mathrm{Gd}^{3+}$ ion to $\mathrm{Tb}^{3+}$ ion is very important for materials used in the field of neutron measurements. Because the gadolinium ion interacts with the neutron, the $\mathrm{Gd}^{3+}$ ion moves into an excited state, and then transfers energy to the $\mathrm{Tb}^{3+}$ ion for emission. In the TL measurement, the green emission of the $\mathrm{Tb}^{3+}$ ion at $542 \mathrm{~nm}$ due to ${ }^{5} \mathrm{D}_{4} \rightarrow{ }^{7} \mathrm{~F}_{5}$ transition is predominating and this green emission is also well-consistent with the sensitivity range of photomultiplier tube in the TL reader.

$\mathrm{K}_{2} \mathrm{GdF}_{5}$ doped with 5, 10, 15, $20 \mathrm{~mol} \% \mathrm{~Tb}^{3+}$ were irradiated by the ${ }^{241} \mathrm{Am} / \mathrm{Be}$ neutron source $\left(10^{7} \mathrm{n} \mathrm{s}^{-1}\right.$ activity). All the samples were placed inside a $25 \mathrm{~cm}$ diameter polyethylene sphere (the polyethylene sphere is used to thermalize as the neutron beam), distance from the sphere to the ${ }^{241} \mathrm{Am} / \mathrm{Be}$ source was $1 \mathrm{~m}$ and irradiation time was $24 \mathrm{~h}$. The TL-glow curves were investigated with heating rate $\beta=10^{\circ} \mathrm{C} \mathrm{s}^{-1}$, the preheat temperature was $50^{\circ} \mathrm{C}$ for $10 \mathrm{~s}$, the temperature range for TL measurements was from 50 to $350^{\circ} \mathrm{C}$, for comparison purpose, the common dosimeter $\mathrm{CaSO}_{4}: \mathrm{Dy}^{3+}$ was also investigated together.

Figure 9a presents the TL-glow curves of the $\mathrm{K}_{2} \mathrm{GdF}_{5}: \mathrm{Tb}^{3+}$ and $\mathrm{CaSO}_{4}: \mathrm{Dy}^{3+}$ samples. The TL intensity of $\mathrm{K}_{2} \mathrm{GdF}_{5}$ : $10 \mathrm{~mol} \% \mathrm{~Tb}^{3+}$ is the highest. In particular, with the thermal neutron irradiation, the TL intensity of $\mathrm{K}_{2} \mathrm{GdF}_{5}: \mathrm{Tb}^{3+}$ $10 \mathrm{~mol} \%$ is 10 times higher than that of the common dosimeter $\mathrm{CaSO}_{4}: \mathrm{Dy}^{3+}$, thus the $\mathrm{K}_{2} \mathrm{GdF}_{5}: \mathrm{Tb}^{3+}$ absorbs significant amount of neutrons. 

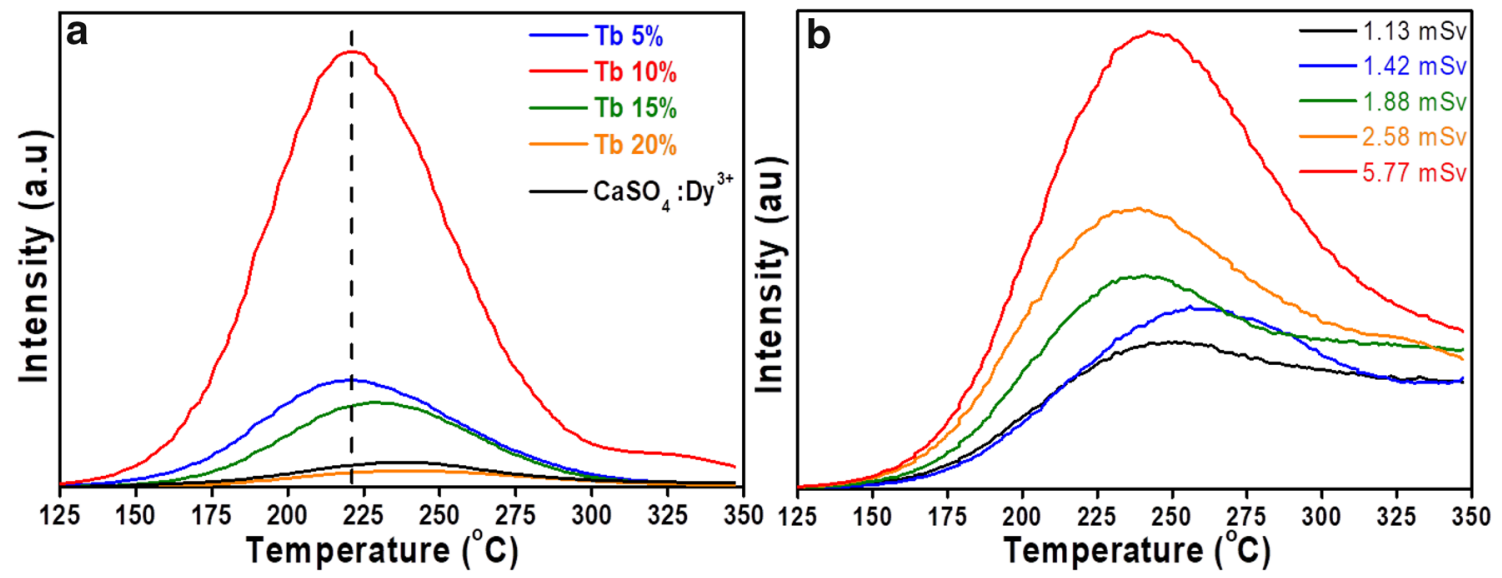

Figure 9. The TL-glow curves: (a) samples irradiated by thermal neutron and (b) $\mathrm{K}_{2} \mathrm{GdF}_{5}: 10 \mathrm{~mol} \% \mathrm{~Tb}^{3+}$ irradiated by fast neutron.

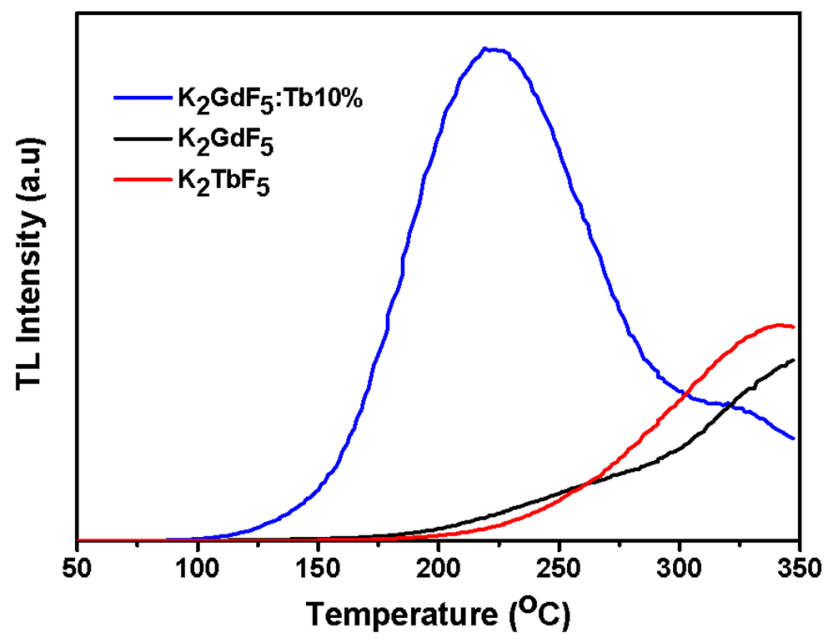

Figure 10. TL-glow curves of $\mathrm{K}_{2} \mathrm{GdF}_{5}: 10 \mathrm{~mol} \% \mathrm{~Tb}, \mathrm{~K}_{2} \mathrm{GdF}_{5}$ and $\mathrm{K}_{2} \mathrm{TbF}_{5}$ irradiated by fast neutron.

The results also show that the shapes of curves are very simple, with the main peak temperature at about $223^{\circ} \mathrm{C}$ (at a heating rate of $10^{\circ} \mathrm{C} \mathrm{s}^{-1}$ ). The TL intensity of the main peak is very high and its shape is quite symmetric, corresponding to the second-order kinetic of TL theory. In the TL theory for the dosimeter, the peak temperature must not be too low to avoid the fading phenomena, as well as not too high to avoid being obscured by infrared, and this peak shown in figure 9 , which is in the range of $200-250^{\circ} \mathrm{C}$ is very suitable for dose measurement. Figure $9 \mathrm{~b}$ shows the TL-glow curves of the $\mathrm{K}_{2} \mathrm{GdF}_{5}: \mathrm{Tb}^{3+} 10 \mathrm{~mol} \%$ irradiated by the various fast neutron doses. The shapes of glow curves are heterogeneous, however, all peaks of glow curves are at the temperature range of $230-250^{\circ} \mathrm{C}$ and the TL intensities of the main peak are proportional to the irradiation doses.

$I_{\mathrm{D}}$ compare TL response of the prepared samples, the samples were irradiated with a neutron beam of $8.31 \mathrm{mSv}$. The results show that the TL response of $\mathrm{K}_{2} \mathrm{GdF}_{5}: \mathrm{Tb}^{3+} 10 \mathrm{~mol} \%$ sample was higher than that of $\mathrm{K}_{2} \mathrm{GdF}_{5}$ and $\mathrm{K}_{2} \mathrm{TbF}_{5}$ samples as shown in figure 10. The TL phenomenon is due to the electron traps and recombination centres in the forbidden bands of the electronic band structure and the formation of these traps and centres requires the doping of different ions. Thus, pure $\mathrm{K}_{2} \mathrm{GdF}_{5}$ and $\mathrm{K}_{2} \mathrm{TbF}_{5}$ crystals will have a very weak TL. In addition, the PL spectrum of $\mathrm{K}_{2} \mathrm{GdF}_{5}$ indicates that the luminescence of $\mathrm{Gd}^{3+}$ ion was not observed in visible light, so the TL intensity of $\mathrm{K}_{2} \mathrm{GdF}_{5}$ was very weak. The TL-glow curves of $\mathrm{K}_{2} \mathrm{GdF}_{5}$ and $\mathrm{K}_{2} \mathrm{TbF}_{5}$ have no peak in the temperature range required for the dosimetry (about $200-300^{\circ} \mathrm{C}$ ), therefore, $\mathrm{K}_{2} \mathrm{GdF}_{5}$ and $\mathrm{K}_{2} \mathrm{TbF}_{5}$ cannot be used as a TL dosimeter. The study results reinforce the neutron dosing characteristics of $\mathrm{K}_{2} \mathrm{GdF}_{5}: \mathrm{Tb}^{3+}$, with the $\mathrm{Gd}^{3+}$ ion absorbing the energy of the neutron and the $\mathrm{Tb}^{3+}$ ion acts as the luminescence centre.

In the case of irradiation by thermal neutron radiation, the results in figure 9a show that the TL intensity of $\mathrm{K}_{2} \mathrm{GdF}_{5}: \mathrm{Tb}^{3+}$ $10 \%$ is much higher than that of the common dosimeter $\mathrm{CaSO}_{4}: \mathrm{Dy}^{3+}$. Therefore, the $\mathrm{K}_{2} \mathrm{GdF}_{5}: \mathrm{Tb}^{3+}$ can be applied as a dosimeter to analyse and measure the nuclear radiation doses.

\section{Conclusion}

The $\mathrm{K}_{2} \mathrm{GdF}_{5}: \mathrm{Tb}^{3+}$ samples synthesized by the solid-state reaction method had a porous surface and a high contact area due to the formation of grooves on the surface. With this special surface feature, the material can be potential for absorbing maximum energy as well as for high luminescence intensity. In addition, the doping with $\mathrm{Tb}^{3+}$ rare-earth ion also enhances emission intensity via the supreme efficiency of energy transfer from $\mathrm{Gd}$ to $\mathrm{Tb}$ ions, and the effects of these surfaces and ion-doped has been shown in PL measurements. In particular, this study has shown the excellent TL properties of $\mathrm{K}_{2} \mathrm{GdF}_{5}: \mathrm{Tb}^{3+}$ related to nuclear radiation, especially 
with neutron. The results of the TL investigation indicate that the material has a linear dose response and high sensitivity to nuclear irradiation. Furthermore, the TL-glow curve shape is suitable for applications in the field of dosimetry. Thus, with the structure and luminescence properties investigated in this study, the $\mathrm{K}_{2} \mathrm{GdF}_{5}: \mathrm{Tb}^{3+} 10 \mathrm{~mol} \%$ will not only satisfy expectations in the optical field, but also presents a feasible idea for a new dosimeter to measure mixed radiation dose.

\section{Acknowledgements}

This work is supported by the Vietnam Academy Science and Technology on research Project VAST03.06/17-18.

\section{References}

[1] Qiufeng S, Fangtian Y, Shihua H, Hongshang P, Yan H and Ye T 2014 J. Lumin. 152138

[2] Deyin W, Nobuhiro K, Lei Z and Yuhua W 2010 J. Electrochem. Soc. 157233

[3] Peijzel P S, Vermeulen P, Schrama W J M and Meijerink A 2005 Phys. Rev. B 71125

[4] Yanguang Q, Xiantao W, Xinyue L, Yonghu C and Min Y 2014 J. Lumin. 15258

[5] Azorın J N, Khaidukov N M, Rodriguez A S and Azorın V J C 2007 Nucl. Instrum. Methods B 26336

[6] Molina P, Santiago M, Marcazzó J, Spano F, Khaidukov N and Caselli E 2011 Radiat. Meas. 461361

[7] Qian S, Huang L, Zhao S and Xu S 2017 J. Rare Earths 35 787
[8] Ye J, Qingping W, Hongpeng Z, Liangliang Z and Jiahua Z 2016 Ceram. Int. 423309

[9] Mares J A, Nikl M, Nitsch K, Solovieva N, Krasnikov A and Zazubovich S 2001 J. Lumin. 94-95 321

[10] Yong Z, Jingwen L, Ning D, Shan J, Tao Z and Jiayu L 2015 J. Non-Cryst. Solids 423-424 30

[11] Xin Y S, Qing M Y, Pan G, Hong S W and Peng X 2015 J. Lumin. 16540

[12] Lili H, Yuhua W, Jia Z and Ye T 2014 Mater. Chem. Phys. 143 476

[13] Xin-Yuan S, Shi-Ming H, Mu G, Qing-Chun G, Xiao-San G and Zi-PiaoY 2010 Phys. B 405569

[14] Faria L O et al 2004 Radiat. Prot. Dosim. 112435

[15] Silva E C et al 2013 Radiat. Meas. 59119

[16] Hanh H K et al 2010 Nucl. Instrum. Methods Phys. Res. Sect. B 2683344

[17] Kui H W, Lo D, Tsang Y C, Khaidukov N M and Makhov V N 2006 J. Lumin. 11729

[18] Ha X V, Nguyen C T and Doan P T T 2014 J. Nucl. Sci. Technol. (Vietnam) 447

[19] James O E, I-Ching L, Malgorzata M L, Paul M B, Alexandra N, Robert A L and Richard E R 1996 Thermochim. Acta 286 233

[20] Chi F, Hu F, Wei I X, Chen Y and Yin M 2017 J. Rare Earths 35436

[21] Mahiou R, Metin J, Fournier M T, Cousseins J C and Jacquier B 1989 J. Lumin. 151

[22] Kesavulu C R, Kim H J, Lee S W, Kaewkhao J, Kaewnuam E and Wantana N 2017 J. Alloys Compd. 704557

[23] Te-Ju L, Li-Yang L, Eric W D, Teng-Ming C, Bing-Ming C and Chien-Yueh T 2006 Appl. Phys. Lett. 89131121

[24] Chenggang Z, Anxian L, Ligang Z, Zhihua Z and Woyun L 2011 Spectrochim. Acta Part A 82406 